\title{
The fractography analysis of IN718 alloy after three-point flexure fatigue test
}

\author{
Juraj Belan ${ }^{1, *}$, Alan Vaško ${ }^{1}$, Lenka Kuchariková $^{1}$, Eva Tillová $^{1}$ \\ ${ }^{1}$ University of Žilina, Faculty of Mechanical Engineering, Department of Materials Science, \\ Univerzitná 8215/1, 01026 Žilina, Slovakia
}

\begin{abstract}
In this study, the high cycle fatigue (HCF) properties of IN718 superalloy with given chemical composition were investigated at three-point flexure fatigue test at room temperature. INCONEL alloy 718 is nickel-chromium-iron hardenable alloy and due to its unique combination of mechanical properties (high-strength; corrosionresistant and so on) used for production of heat resistant parts of aero jet engine mostly. Mechanical properties of this alloy are strongly dependent on microstructure and on presence of structural features such are principal strengthening phase gamma double prime, gamma prime and due to its morphology less desired delta phases. The mentioned phases precipitate at various temperature ranges and $\mathrm{Nb}$ content as well. The three-point flexure fatigue test was performed on ZWICK/ROELL Amsler 150 HFP 5100 test equipment with approximate loading frequency $\mathrm{f}=150 \mathrm{~Hz}$. The $\mathrm{S}-\mathrm{N}$ (Stress - Number of cycles) curve was obtained after testing. With the help of scanning electron microscope (SEM), fractography analyses were performed to disclose the fracture features of specimens in different life ranges. The brief comparison of three-point flexure and push-pull fatigue loading modes and its influence on fatigue life is discussed as well.
\end{abstract}

Keywords: IN 718 alloy, low frequency fatigue loading, three-point flexure, fatigue crack initiation, fatigue crack propagation, S-N curve, SEM observing, fractography analysis

\section{Introduction}

Ni-base superalloys such as IN718 derive their strength from the solid solutions of alloying elements, and to even greater extent from precipitates within the solid solution matrix. Nibase superalloys are widely used for structural applications at high temperature, especially where creep and fatigue are the important deformation modes. Among the Ni-base superalloys, Inconel 718 (IN718) is predominantly used in high-temperature applications due to its highly satisfactory price/overall performance ratio, good corrosion resistance and mechanical properties with excellent weldability. The major applications of this alloy are turbine discs in gas turbine engines. However, its mechanical properties are degraded at temperatures above $650^{\circ} \mathrm{C}[1]$.

\footnotetext{
* Corresponding author: juraj.belan@fstroj.uniza.sk

Reviewers: Richard Pastirčák, Marta Kianicová
} 
The microstructures of Ni-base superalloys are composed of a face-centred cubic matrix $\gamma$ (Ni stacked on Ni plus Fe), with large additions of alloying elements that give solution hardening, corrosion resistance and a low stacking fault energy. The strengthening $\gamma^{\prime}(\sim 1 / 3 \mu \mathrm{m})$ and $\gamma^{\prime \prime}(\sim 1 / 20 \mu \mathrm{m})$ precipitates are randomly interspersed throughout the $\gamma$ matrix and at grain boundaries; it is these that make the lattice planes highly resistant to slip band formation at high temperature [2].

While microstructurally simple, superalloys are chemically complex. In addition to Al, they have Ti (substitutes for Al in the $\gamma^{\prime}$, Fig. 1a, increases the fraction of $\gamma^{\prime}$, and decreases the fault energy in the $\gamma^{\prime}$ ), Cr (primarily in $\gamma$, confers oxidation resistance), Mo (in both $\gamma$ and $\gamma^{\prime}$, may increase or decrease the relative mismatch depending on other elements). Some residual carbon may be present in alloys used for discs (relatively low temperature) as a processing impurity while in other alloys it may be intentionally added to form carbides which reduce creep by inhibiting grain boundary sliding. Other elements may be added to provide solid solution strengthening, (e.g. Ta) to control the volume fraction of $\gamma^{\prime}$, to inhibit grain boundary sliding by migrating to boundaries (e.g. odd size atomic species such as $\mathrm{Zr}$ ), to improve castability (Hf) and to control the shapes of carbides (Hf). The volume fraction of $\gamma^{\prime}$ in these alloys ranges from $25 \%$ to over $50 \%$, with more modern alloys having a higher volume fraction. The effect of various elements on superalloys has been widely studied and much detailed information may be found in various references [3-5].

a)

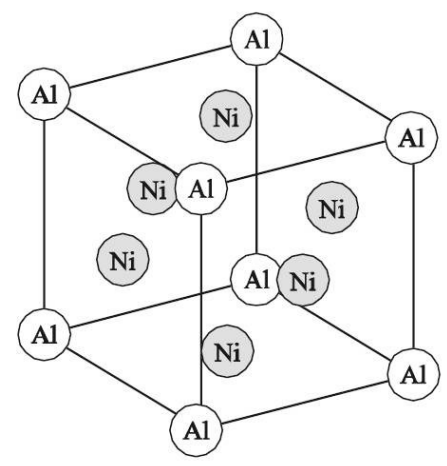

Fig. 1. (a) Crystal structure of $\mathrm{Ni}_{3} \mathrm{Al} \gamma^{\prime}$. In the idealized structure there are three complete atoms at the centres of the cube faces and one complete atom at the cube corners. The FCC-like crystallographic structure is designated as $\mathrm{L}_{2}$; (b) Crystal structure of $\gamma^{\prime \prime}$. This crystal structure is denoted $\mathrm{DO}_{22}$ and may be viewed as stacking two FCC-like ordered unit cells to produce the complete unit cell [7].

Over the years, as the function of various elements has become better understood, compositions have been simplified. Superalloy processing depends on the intended application. The major forms in which they are used are:

a) single crystals (for jet engine turbine blades, with [001] axis aligned along the blade axis);

b) directionally solidified (DS) which are polycrystalline but with all crystals aligned longitudinally in the [001] direction (for land-based turbines);

c) billets formed from forged or rolled ingots (disks);

d) powder metallurgy products (HIP or HIP + Forged, used in jet engine disks).

Similar considerations apply to the Ni-Fe base superalloys such as In 718 which, in addition to $\mathrm{Fe}$, also contains $\mathrm{Nb}$ to form coherent precipitates with a disk-like structure [6] in an FCC $\gamma$ matrix. These precipitates have a $\mathrm{DO}_{22}$ crystal structure, and are based on the 
$\mathrm{Ni}_{3} \mathrm{Nb}$ ordered compound shown in Fig. $1 \mathrm{~b}$, and are denoted by $\gamma^{\prime \prime}$. As with the $\gamma^{\prime}$ Ni-base alloys, alloying elements such as Al and Ti may be added and also occupy the $\mathrm{Nb}$ sites. The $\gamma^{\prime \prime}$ precipitates have a disc-like shape with the small dimension aligned along the three [001] directions. In addition, there are some $\gamma^{\prime}$ precipitates present on which the particles $\gamma^{\prime \prime}$ have been shown to precipitate. These alloys are primarily used for disks in jet engines as well as components in the power generation industry. Components from these alloys are generally produced by traditional ingot metallurgy followed by mechanical forming to obtain a uniform fine grain size (ASTM 6-7).

The aim of this study is to provide information about three point flexure fatigue test at room temperature made at low frequency with sinusoidal loading applied on simple blocky shape specimens. The frequency of fatigue test varied from 143 up to $151 \mathrm{~Hz}$. Employed static force of fatigue test was set on value $F=-15 \mathrm{kN}$. The dynamic loading as itself changes from $6.31 \mathrm{kN}$ up to $12.8 \mathrm{kN}$. The number of cycles $2.10^{7}$ (according to standard for this kind of non-ferrous alloys is number of cycles up to $10^{7}$ considered as fatigue lifetime limit) was considered as fatigue life limit. Next S-N curve were plotted and also scanning electron microscope (SEM) fracture surface analysis was done with focus to describe micro-mechanism of initiation and fatigue crack propagation (FCP) in Inconel 718 alloy. Received data was compared with results of other authors who made fatigue tests at the same experimental material but at different fatigue loading.

\section{Experimental material and methods}

The wrought Ni-Fe alloy 718 was used as an experimental material. The chemical composition of our material was (in wt. \%): $\mathrm{C}-0.026$; $\mathrm{Si}-0.09 ; \mathrm{Mn}-0.07$; $\mathrm{P}-0.008$; $\mathrm{S}<0.001 ; \mathrm{Al}-0.57$; $\mathrm{B}-0.004$; $\mathrm{Bi}(\mathrm{ppm})<0.1 ; \mathrm{Co}-0.14 ; \mathrm{Cr}-19.31 ; \mathrm{Cu}-0.03$; $\mathrm{Mo}-$ 2,$99 ; \mathrm{Nb}-5.30 ; \mathrm{Ni}-53.32 ; \mathrm{Pb}(\mathrm{ppm})-0.1 ; \mathrm{Se}(\mathrm{ppm})<3$; $\mathrm{Ta}<0.01 ; \mathrm{Ti}-0.96 ; \mathrm{Ni}+\mathrm{Co}-$ 53.46; $\mathrm{Nb}+\mathrm{Ta}-5,31 ;$ and $\mathrm{Fe}-$ balance.

The experimental material was heat treated, according to the supplier's BIBUS Ltd. (CZ) material sheet, $980{ }^{\circ} \mathrm{C} / 1 \mathrm{hrs}$. AC + heating at $720^{\circ} \mathrm{C} / 8 \mathrm{hrs}$. followed $\mathrm{FC}\left(50{ }^{\circ} \mathrm{C}\right.$ per hour) to temperature $620{ }^{\circ} \mathrm{C}$ holding time $8 \mathrm{hrs}$. and air cooled. Achieved mechanical properties of material with grain size ASTM 12 are in Table 1.

Table 1. Mechanical properties of IN 718 as received from BIBUS Ltd. after applied heattreatment and for grain size ASTM 12.

\begin{tabular}{|l|l|l|}
\hline \multirow{2}{*}{} & \multicolumn{2}{|l|}{ Temperature $\left[{ }^{\circ} \mathrm{C}\right]$} \\
\cline { 2 - 3 } & 20 & 649 \\
\hline Yeld strength, Rp 0.2 [MPa] & 1213 & 986 \\
\hline Maximum strength, Rm [MPa] & 1549 & 1123 \\
\hline Elongation, A [\%] & 21.3 & 22.6 \\
\hline Reduction area, Z [\%] & 33.3 & 68.0 \\
\hline Hardness, HB 10/3000 & 429 & - \\
\hline Creep rupture, $\sigma_{\mathrm{T} / 649}[\mathrm{MPa}]$ & - & 689 \\
\hline Rupture life [hrs.] & - & 26.8 \\
\hline Creep elongation, $\mathrm{A}_{\text {creep }}[\%]$ & - & 45.7 \\
\hline
\end{tabular}


The experimental material of mentioned chemical composition was cut into simple blocky samples with dimensions (b x h x l) $11 \mathrm{~mm} \times 10 \mathrm{~mm} \times 56 \mathrm{~mm}$ where side of sample under fatigue loading was polished to avoid unwanted fatigue crack initiation from surface roughness. The three point flexure fatigue tests, Fig. 2, has been carried out on testing machine ZWICK/ROELL Amsler 150 HFP 5100 at room temperature with static pre-load $F_{\text {static }}=-15 \mathrm{kN}$ and dynamic force $F_{\text {dynamic }}$ varying from $6.31 \mathrm{kN}$ up to $12.8 \mathrm{kN}$. The value of $2.10^{7}$ numbers of cycles was set as reference and when specimen has reached this value without break, so called runout, that bending stress was considered as fatigue lifetime limit. The frequency of fatigue tests was approximately $f=150 \mathrm{~Hz}$. The S-N curve was plotted from measured values, which gives relation between maximum bending stress $\sigma_{\text {omax }}$ and number of cycles $N_{f}$.

For calculation of maximum bending stress formula (1) was used:

$$
\sigma_{\text {omax }}=\frac{3 \times F \times L}{2 \times b \times h^{2}} \quad[\mathrm{MPa}]
$$

where $\sigma_{\text {omax }}$ is maximum bending stress [MPa], $F-$ is dynamic load [N], $L$ - distance of supports [mm], $b$ - specimens width [mm], and $h-$ is specimen high [mm].

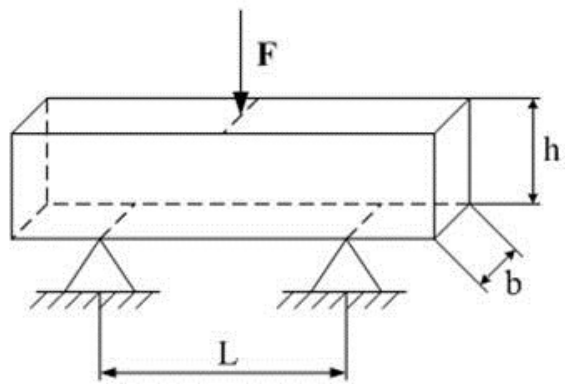

Fig. 2. A schematic drawing of setting three point flexure fatigue test

The fractography analysis of broken specimens was also done. For fractography analysis scanning electron microscope TESCAN Vega II LMU was used. All fractography analysis was done in order to describe micro-mechanisms of fatigue crack initiation, fatigue crack propagation (FCP) and final static fracture of specimens.

\section{Results and discussion}

A typical microstructure of wrought alloy 718 is on Fig.3. The microstructure consist of light grey blocks of carbides and fine lenticular and lamellar particles of delta phase $\left(\mathrm{Ni}_{3} \mathrm{Nb}\right)$ distributed in the FCC matrix, with grain size approximately $10 \mu \mathrm{m}$ and a few deformation twins. In some cases, especially after long temperature dwell coarse $\gamma^{\prime}$ phase and more delta phases are also visible.

For low frequency fatigue testing were used 10 specimens with simple blocky shape as seen at Figure 2. Figure 4 shows the S-N curve of IN718 obtained from the three point flexure fatigue tests at room temperature with frequency $150 \mathrm{~Hz}$ under the load ratio of $R=$ 0.11 . Obtained results were approximated with equation (2) what is a Basquin formula for $\mathrm{S}-\mathrm{N}$ presentation and approximation.

$$
\sigma_{a}=2591 \times N_{f}^{-0.0811}
$$

where $\sigma_{\mathrm{f}}{ }^{\prime}=2591$ is a coefficient of fatigue strength and $-0.0811=\mathrm{b}$ is lifetime curve exponent. 


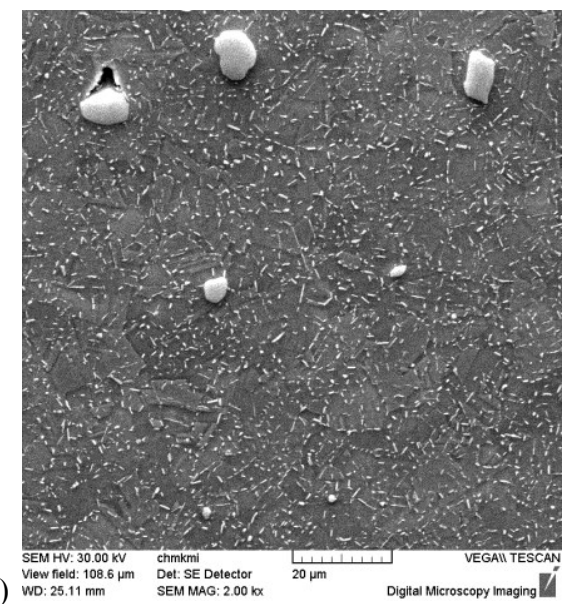

a) WD: $25.11 \mathrm{~mm}$

Det: SE Detector
SEM MAG: $2.00 \mathrm{hx}$

b)

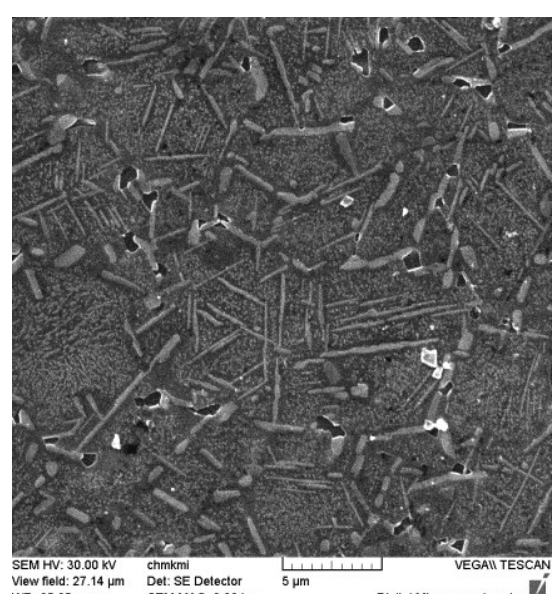

Fig. 3. Micrographs of wrought Inconel alloy 718, with presence of a) delta $\mathrm{Ni}_{3} \mathrm{Nb}$ phase and primary carbides $\mathrm{NbC}$, and b) coarse $\gamma^{\prime}$ phase with more delta presence, SEM, etch. Kallings.

From measured S-N curve is clearly seen that the fatigue life increases with decreasing stress amplitude and the S-N curve appears to continuously decline as the life extends. The limit number of cycles $2.10^{7}(20000$ 078) was reach at maximum bending stress $\sigma_{\text {omax }}=740 \mathrm{MPa}$.

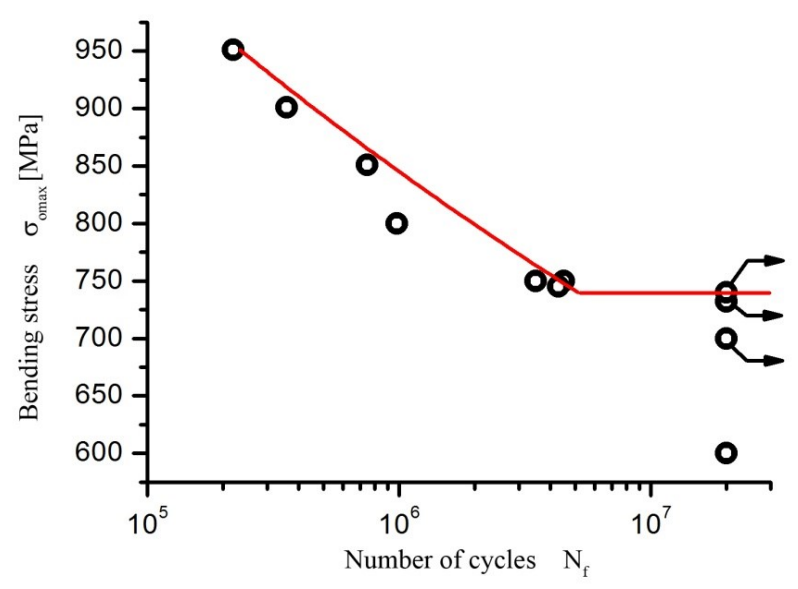

Fig. 4. The S-N curve for three point flexure fatigue test of Inconel alloy 718 with runouts after reaching $2.10^{7}$ numbers of cycles.

According fatigue lifetime stress obtained at different testing method - ultrasonic pushpull loading with $R=-1[8-10]$; is this result about one time higher (push-pull fatigue lifetime about $386 \mathrm{MPa}$ compared to three point flexure fatigue lifetime $740 \mathrm{MPa}$ at the same number of cycles). Of course, these values may be compared only roughly because of different frequency of test and different mechanism of loading.

Since Ni-base and Fe-Ni base alloys are used in jet engine discs, where both fatigue crack propagation and low cycle fatigue (LCF) are important in design. During fatigue in a strain controlled test, the stress responds in accordance to the applied strain levels and the influence of the microstructure. When an annealed specimen undergoes strain control 
fatigue, the stress generally increases with increasing cycling for a certain number of cycles. Depending on the deformation mode and its internal stress state, the response stress will either stabilize or reach a maximum value followed by softening. The response stress is also dependent upon the test temperature, strain rate and the applied plastic strain amplitude since these variables strongly influence the deformation substructure [7]. It is understood that the variation of frequency affects the fracture mode of this material. At higher frequencies transgranular failure occurs, as fatigue dominates, while at lower frequencies creep/oxidation exert greater influence. Shahinian and Sadananda [11] describe their observation that the fatigue crack growth rate (FCGR) increases with increasing stress ratio. Furthermore, the mode of fracture is transgranular in vacuum and, at relatively high frequency of loading, also in air, while it is predominantly intergranular in an oxidising environment at intermediate frequencies. Different fatigue crack growth mechanisms in IN718 alloy have been proposed by various researchers to describe different effects listed above. Andersson and Persson [12] carried out microscopic examination of fatigue crack surfaces in Inconel 718 using scanning electron microscope at room temperature, and observed two different kinds of fracture surfaces: locally flat fracture surfaces, and striations. It was confirmed by Andersson and Persson that both mechanisms are likely to be active simultaneously, but their effects are not additives. It was also concluded that crack growth was dominated by the crystal slip-based mechanism. Even so, striations could be found only in a few grains.

The occurrence of ductile striations on fracture surfaces indicates the presence of the transgranular (ductile) fracture mechanism of FCG at room temperature. The spacing between striations (i.e., crack growth rate) increased with the stress intensity factor range. Andersson and Persson's room temperature experiments proved the dominance of transgranular crack growth mechanism for all cases examined under various $\Delta \mathrm{K}$ and maximum stress values. Nevertheless, different crack growth mechanisms were identified in this analysis, such as microcracking followed by subsequent linking, and pure shearing. Grain orientation exerted a strong influence on transgranular crack propagation and the crack growth rate da/dN, due to the interaction between different mechanisms active simultaneously. Andersson and Persson state that rough surfaces created by striations and crack meandering induce premature crack closure. Crack growth was predominantly found to occur either by growth on slips planes in a shearing mode, or by linking of microcracks ahead of the main crack, which did not require detectable crack opening.

All this fact about fatigue crack initiation, stable fatigue crack propagation, pretty close correspond to result received after three point flexure fatigue testing at room temperature which has been done at our experiment, as report Fig. 5 .

Fig. $5 \mathrm{a}$ and $5 \mathrm{~b}$ are showing initiation sites of fatigue crack at high and lower cyclic loading. The free surface at lower frequency of loading and so called „fish-eye“ at higher frequency of loading are common as initiation sites. In this case, no evidence of „fish-eye“ or initiation from undersurface oxides was observed. Figures $5 \mathrm{c}$ and $5 \mathrm{~d}$ represent the stable area of fatigue crack propagation characterised by transcrystalline ductile mechanism with striation presence. However, at same cases, especially at different mode of loading (e. g. push-pull loading) is this second area of fatigue fracture characterised with mix of fatigue crack growth mechanism - starts as transcrystalline through small intercrystalline growth and finally transcrystalline again. As shows Fig. 5c, intercrystalline cleavage with facets and river morphology is presented in a few places of fracture surface.

The distance of striation shows fatigue crack growth a tone cycle loading. At higher values of loading is occurred also secondary fatigue crack perpendicular to major fatigue crack, Fig. 5e. The last Fig. 5f shows a final stage of fatigue test, static fracture, which represents the third stage. Mechanism of fracture is strictly ductile transcrystalline with dimple morphology where crushed primary carbides $\mathrm{NbC}$ can be observed. 


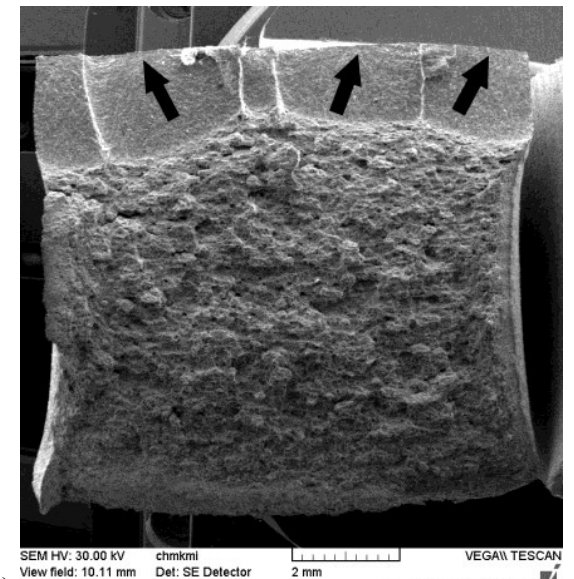

a)
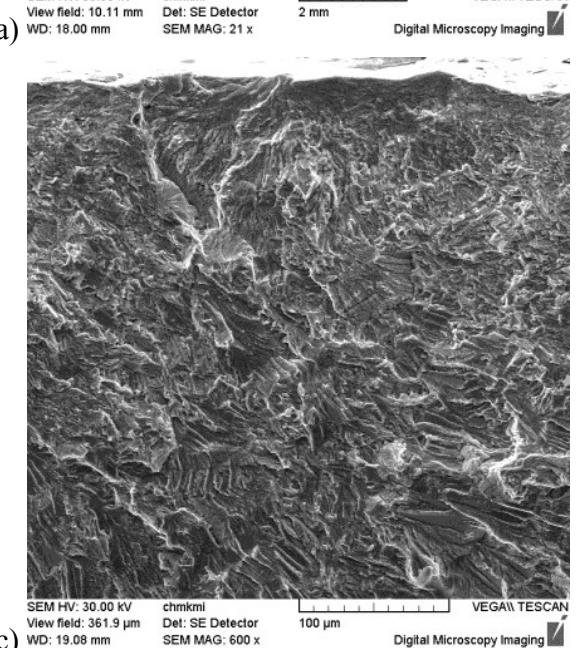

$\begin{array}{ll}\text { C) WD: } 19.08 \mathrm{~mm} & \text { Det: SE Detector } \\ & \text { SEM MAG: } 600 \mathrm{x}\end{array}$

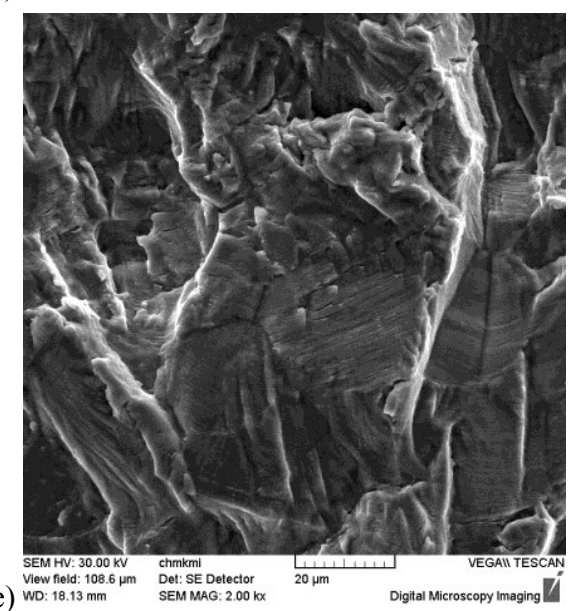

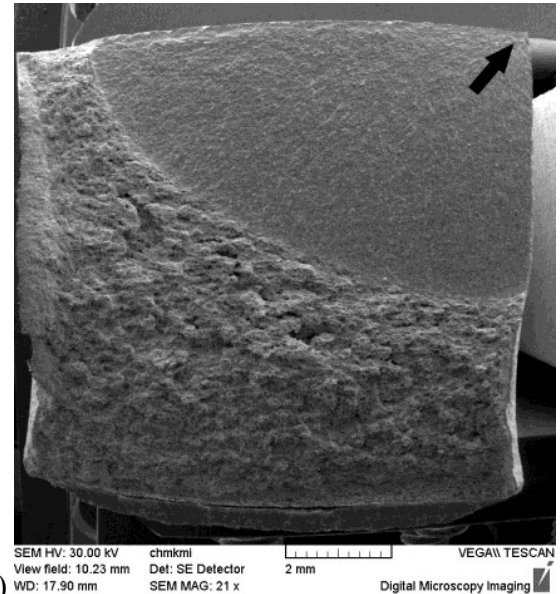

b)
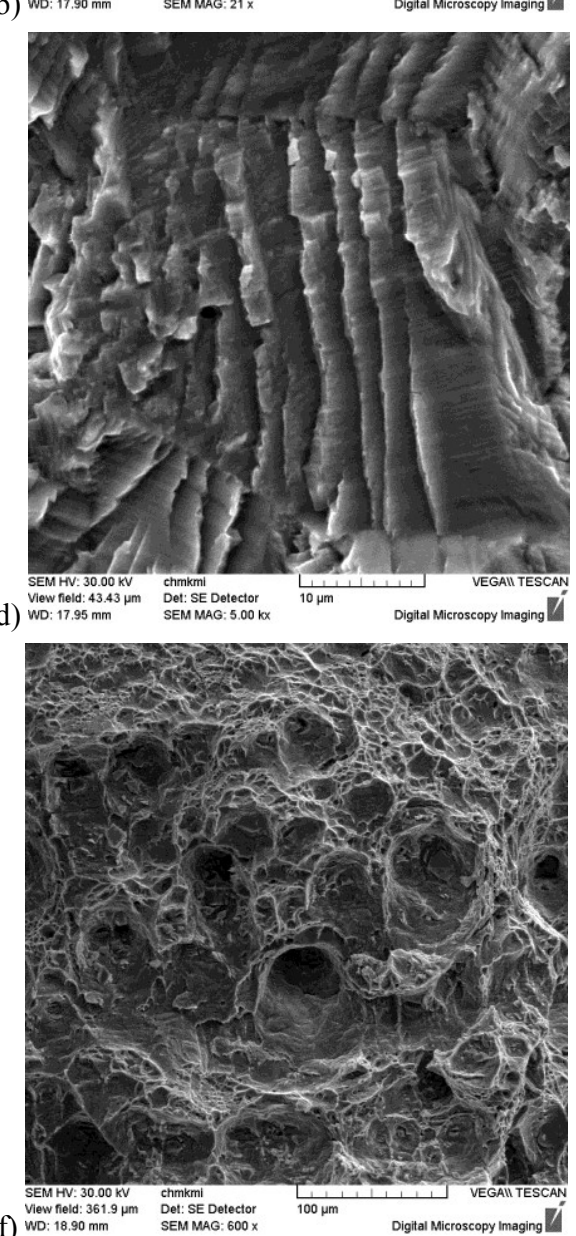

Fig. 5. Fractography surfaces of Inconel 718 after three point flexure fatigue test, SEM: a) initiation site at higher cyclic loading, note three initiation points; b) initiation site at lower cyclic loading, only single one, compared to fig.a; c-d) stable fatigue crack propagation characterised by striation; e) secondary fatigue crack occurrence at higher level of loading; f) static part of fatigue fracture. 


\section{Conclusions}

In this article is given brief information about fractography and fracture mechanism of Inconel alloy 718 under three point flexure bending mode at room temperature. From measured S-N curve is clearly seen that the fatigue life increases with decreasing stress amplitude and the S-N curve appears to continuously decline as the life extends. The limit number of cycles $2.10^{7}$ (20000 078) was reach at maximum bending stress $\sigma_{\text {omax }}=740 \mathrm{MPa}$. Obtained results were compared with experimental results of other authors whose provide their tests at different load condition. Our results show pretty good correlation with their measurements.

The free surface at lower frequency of loading and so called "fish-eye“ at higher frequency of loading are common as initiation sites. In this case, no evidence of "fish-eye“ or initiation from undersurface oxides was not observed. The FCG continue with transcrystalline ductile mechanism with striation presence. At higher values of loading are secondary fatigue crack perpendicular to major fatigue crack also occurred. Mechanism of fracture is strictly ductile transcrystalline with dimple morphology where crushed primary carbides $\mathrm{NbC}$ can be observed.

This work has been supported by Scientific Grant Agency of Ministry of Education of Slovak Republic and Slovak Academy of Sciences, No. 1/0533/15, No. 049ŽU-4/2017 and project EU ITMS 26220220154.

\section{References}

1. D. G. Leo Prakash, M. J. Walsh, D. Maclachlan, A. M. Korsunsky, Crack growth micromechanisms in the IN718 alloy under the combined influence of fatigue, creep and oxidation. International Journal of Fatigue 31, 1966-1977 (2009)

2. D. Boyd-Lee, Fatigue Crack Growth Resistant Microstructures in Polycrystalline Ni-base Superalloys for Aeroengines. International Journal of Fatigue, 21 (4), 393-405 (1999)

3. J. F. Radavich, The Physical Metallurgy of Cast and Wrought Alloy 718. Superalloy 718 Metallurgy and Applications, Ed.: E., A., Loria, The Minerals, Metals \& Materials Society, $229-240$ (1989)

4. C. T. Sims, W. C. Hagel, The superalloys. New York: John Wiley \& Sons; 1972

5. J. K. Tien, T. Caufield, Superalloys, supercomposites and superceramics. New York: Academic Press; 1989

6. D. F. Paulonis, J. M. Oblak, D. S. Duvall, Precipitation in nickel-base alloy 718. Trans ASM 62, 611-622 (1969)

7. Pineau, S. D. Antolovich, High temperature fatigue of nickel - base superalloys. Engineering Failure Analysis 16, 2668-2697 (2009)

8. L. Trško, M. Guagliano, O. Bokůvka, F. Nový, M. Jambor, Z. Florková, Influence of Severe Shot Peening on the Surface State and Ultra-High-Cycle Fatigue Behavior of an AW 7075 Aluminum Alloy. Journ. Of Mat. Eng. and Perf. 26 (6), 2784-2797 (2017)

9. J. Belan, High frequency fatigue test of in 718 alloy - microstructure and fractography evaluation. Metalurgija 54 (1), 59-62 (2015)

10. M. Vaško, M. Blatnický, P. Kopas, M. Sága, Research of weld joint fatigue life of the AlMgSi07.F25 aluminium alloy under bending-torsion cyclic loading. Metalurgija 56 (1-2), 94-98 (2017)

11. P. Shahinian, K. Sadananda, Effects of Stress Ratio and Hold-Time on Fatigue Crack Growth in Alloy 718. J Eng Mater Technol 101, 224-230 (1979)

12. H. Andersson, C. Persson, In-situ SEM study of fatigue crack growth behaviour in IN718. Int J Fatigue 26 (3), 211-219 (2004) 